\title{
DYNAMIC STRENGTH AND FRACTURE BEHAVIOUR OF DUAL-PHASE HIGH STRENGTH STEEL UNDER HIGH STRAIN RATE
}

\author{
Sunil KUMAR M R, Eva SCHMIDOVÁ, Bohumil CULEK, Přemysl HOJKA \\ University of Pardubice, Pardubice, Czech Republic, EU, \\ sunilmr21@gmail.com, Eva.Schmidova@upce.cz
}

https://doi.org/10.37904/metal.2019.716

\begin{abstract}
Dual phase steel has been significantly used in the automotive industry for the outer body parts. It has high strength, good formability and high toughness. Passive safety during a crash is significant, which drives this experimental work. In this research work, dynamic strength and fracture behaviour of the dual phase steel DP500xxx under varying high strain rate has been investigated using pendulum hammer impact testing machine and Electrohydraulic testing machines. The Strain rate sensitivity of the steel and microstructural phase changes are studied at higher strain rates. Thin sheets of dual phase steel are tested with from quasistatic strain rate up to $10^{3} \mathrm{~s}^{-1}$. Fracture mechanism is observed after the impact-tensile tests and strain hardening effect is measured using local hardness measurement. Measurement of local hardness gives the spread of the plastic deformation and nature of strain hardening.
\end{abstract}

Keywords: Dual-phase steel, strain rate sensitivity, dynamic strength, fracture behaviour

\section{INTRODUCTION}

Increased competition and environmental concerns have put a substantial amount of pressure on the reduction of the weight of automotive vehicles to boost efficiency. New types of steels have been used in the automotive industry from several decades with constant upgradations or replacement of the existing steels. Advanced high strength steels are also being used in the various components of the automotive vehicles because of their high strength to weight ratio. Dual-phase steel is one of the advanced high strength steel used in the several components of the automobiles. The usage of the dual phase (DP) steel has been steadily increasing mainly in outer body components like doors, panels, pillars and support structures. Ferritic-martensitic dual phase steels are popularly used in automotive industries. It has good ductility and toughness along with high strength and better strain hardening properties. Since most the components are relatively thin and subjected to first of resistance during the crash, it is important to study the strain rate sensitivity of these steels. The theme of this research work is to find out the sensitivity of the steel to the high strain rate considering different pre-strain conditions, due to the different intensity of forming. The heterogeneous spread of dislocation strengthening during a crash is typical for DP steels and involves the influence of grain and phases morphology [1-6]. That is why the DP steels are becoming a promising combination with nowadays widely used low-alloyed martensitic steel grades $[7,8]$. There are several methods are being used around the world to find the strain rate sensitivity of the thin sheets at high strain rate, which are, one bar method, split Hopkinson tensile bar and other nonconventional methods. Here in our research work, we are using impact pendulum hammer with a specially designed specimen holder for the high strain rate impact tensile strength measurement and electrohydraulic testing machine. After testing samples are inspected in the scanning electron microscope for the microscopic structural phase changes and type fracture behaviour. Jingui Qin and his team have worked on the strain rate sensitivity of the dual phase steels DP500 and DP750 [9]. Peikang Xia and his team use a split Hopkinson tensile bar method (SHTB) and digital image correlation (DIC) technique to study the high strain rate behaviour of thin sheets [10]. Behnam Shakerifard and his team have worked on the strain rate sensitivity of the complex phase steel and constructed Johnson-cook model to relate yield strength and strain rate [11]. 


\section{MATERIALS AND METHODS}

\subsection{Materials}

DP500xxx dual phase steel has been used for this research work; it has both ferrite and martensitic crystallographic structure. Ferrite composition increases the ductility and toughness of the steel, whereas, martensitic structure helps in the higher strength. Chemical composition of DP500xxx is listed in Table 1. Figure 1 shows the SEM image of the steel, contains large ferrite grains with intermediate martensitic structures.

Table 1 Chemical composition (wt.\%)

\begin{tabular}{ccccccccccc}
\hline Sample & $\mathrm{C}$ & $\mathrm{Mn}$ & $\mathrm{Si}$ & $\mathrm{P}$ & $\mathrm{S}$ & $\mathrm{Cr}$ & $\mathrm{Ni}$ & $\mathrm{Cu}$ & $\mathrm{Al}$ & $\mathrm{Ti}$ \\
\hline DP500xxx & 0.083 & 1.72 & 0.026 & 0.021 & 0.0049 & 0.209 & 0.0097 & 0.014 & 0.056 & 0.163 \\
\hline
\end{tabular}

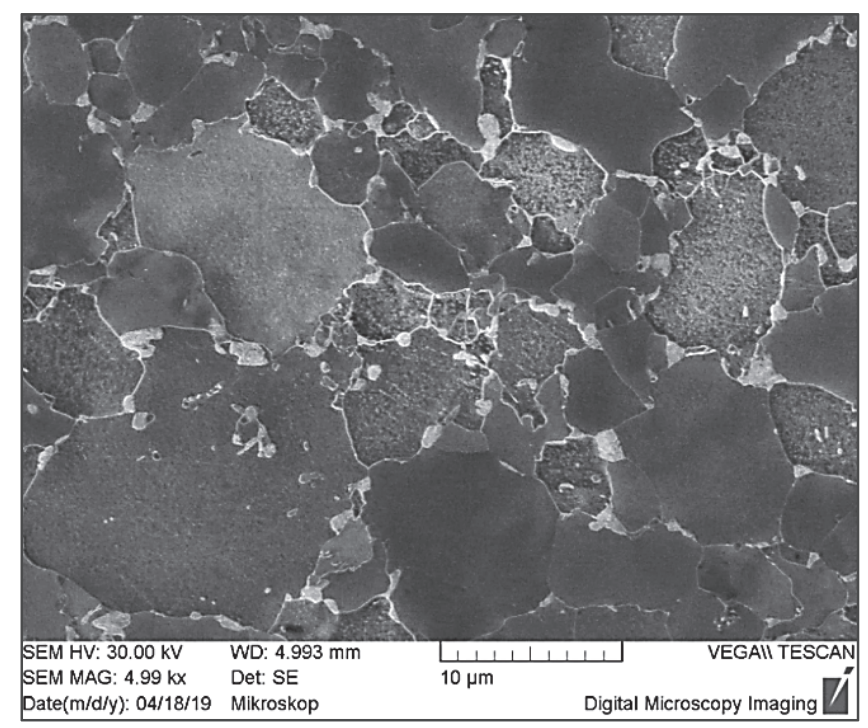

Figure 1 SEM image of DP

\subsection{Pendulum impact hammer and Electro-hydraulic tensile testing}

To find out the strain rate sensitivity of the DP500xxx dual phase steel at high strain rate tensile stresses, Zwick/Roell HI450P pendulum impact hammer is used at a strain rate of $1060 \mathrm{~s}-1$. Samples are prepared from the original car door. The sample is prepared with dogbone shape, having a width of $5 \mathrm{~mm}$ and length of $5 \mathrm{~mm}$ at the gauge section and $15 \mathrm{~mm}$ length and width at the holders. The Sample geometry and dimensions are shown in Figure 2. a special type of holder is designed for holding the thin and small samples during testing. Samples are carefully placed inside the holder and mounted vertically on the hammerhead. The hammerhead is positioned at maximum height to utilize maximum potential energy to release the $450 \mathrm{~J}$ of energy and can produce a velocity of $5.3 \mathrm{~m} / \mathrm{s}$ before hitting the samples. Displacement of the sample, the force transmitted to the sample, time and energy consumed are electronically recorded during the

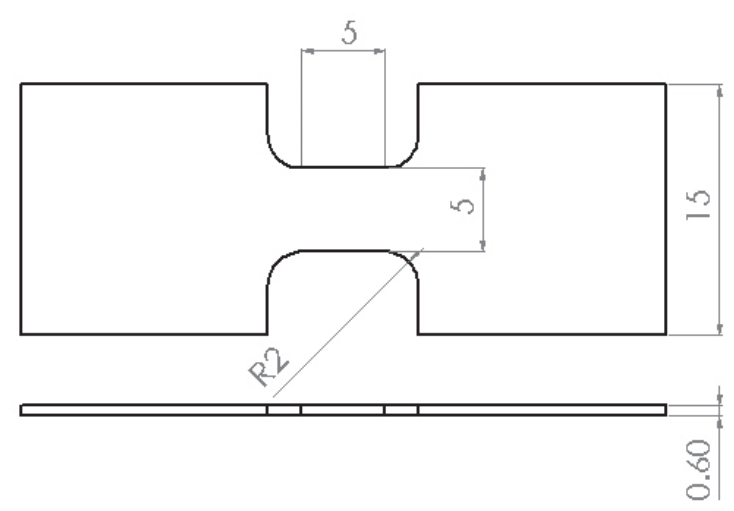

Figure 2 Dimension of specimen used in pendulum hammer impact testing. test from the machine. 
Along with the pendulum impact hammer, Electro-Hydraulic testing machine Inova AH40-300QM561 is also used to measure the strain rate sensitivity of the steel. The test is conducted at a maximum velocity of $5 \mathrm{~m} / \mathrm{s}$. the sample has $9 \mathrm{~mm}$ length and $5 \mathrm{~mm}$ width at the gauge section. Strain gauges are attached just above the gauge section to obtain precise force data. Force data is obtained from both strain gauge and load cell in the machine. Displacement during the testing is recorded using the Messotron DUH300 Keyence LK-H055 laser optic system with high accuracy.

\subsection{Local Hardness measurement}

To find the spread of the plastic deformation after the impact tests, local hardness values are calculated from the fractured end to the unaffected end. Vickers hardness HV0.5 is used in the Zwick/Roell automatic hardness measurement device. After the dynamic test, a sample with proper deformation is selected for hardness measurement. Initially, the sample is cut in horizontal direction then grinded and polished to avoid the artificial effects on hardness values.

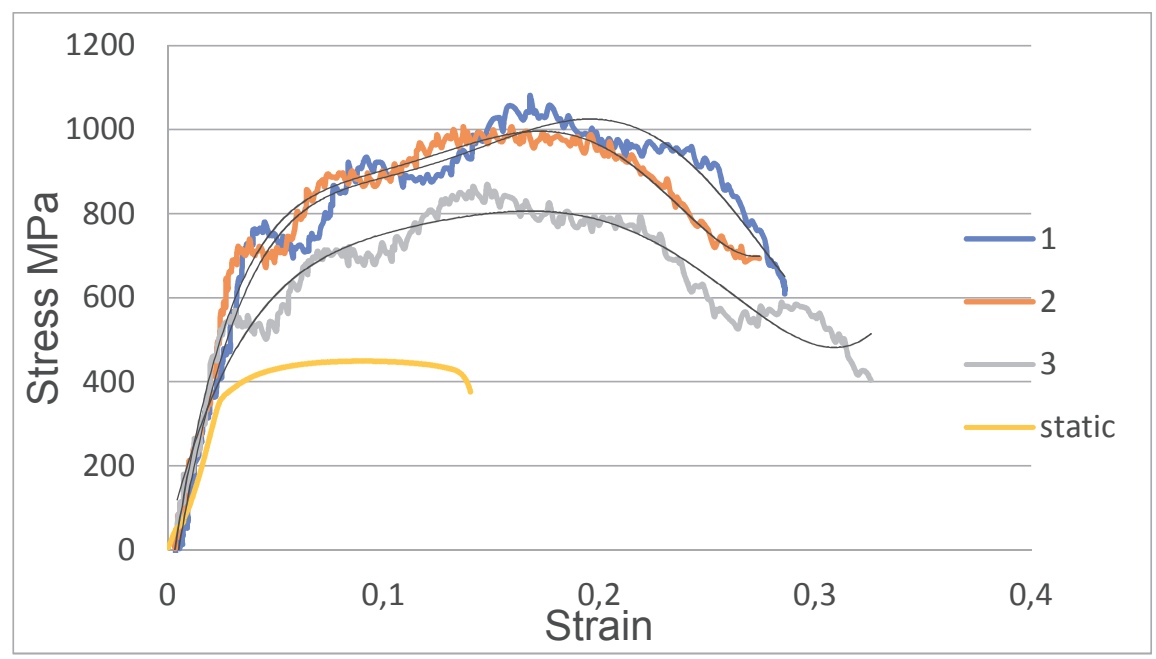

Figure 3 Stress-strain curve of DP500xxx steel from electro-hydraulic testing

\section{RESULTS AND DISCUSSIONS}

\subsection{Strain rate sensitivity}

After conducting the quasi-static and dynamic impact test in the universal tensile testing machine and electrohydraulic testing machine respectively, stress-strain relations are plotted in the graph and shown in Figure 3. A clear conclusion can be made from the data is that this particular steel is sensitive to the strain rate. The quasi-static test gives an ultimate strength of around $450 \mathrm{MPa}$, whereas the results from the electro-hydraulic test give an ultimate tensile strength of 1082, 1007 and $870 \mathrm{Mpa}$ for three samples. The major reason for increasing plastic stresses is the increase of dislocation density during dynamic loading [9]. Dislocations density generation during loading is dependent on number factors like ferrite composition, ferrite-martensite interaction, martensite distribution and fragmentation of martensite during loading [12]. Deviation in the results from the dynamic samples may be attributed to the sample preparation at different parts of the car's door.

Table 2 Dynamic test results from impact pendulum hammer

\begin{tabular}{|l|l|c|c|}
\hline Sample & $\mathbf{1}$ & $\mathbf{2}$ & $\mathbf{3}$ \\
\hline Ultmitae tensile strength (MPa) & 960 & 965 & 930 \\
\hline
\end{tabular}


The results from the pendulum impact hammer are plotted on the graph and ultimate strength is calculated and shown in Table 2. Several samples are tested and few results with lower artificial effects are chosen for analysis. Factors like the geometry of the sample, thickness os the sample, vibration during testing and reflected force waves affect the resulting output. Average values of the force are taken to eliminate the effect of vibration and other artefacts. The average Ultimate tensile strength of the samples is $960 \mathrm{MPa}$.

\subsection{Fracture behaviour}

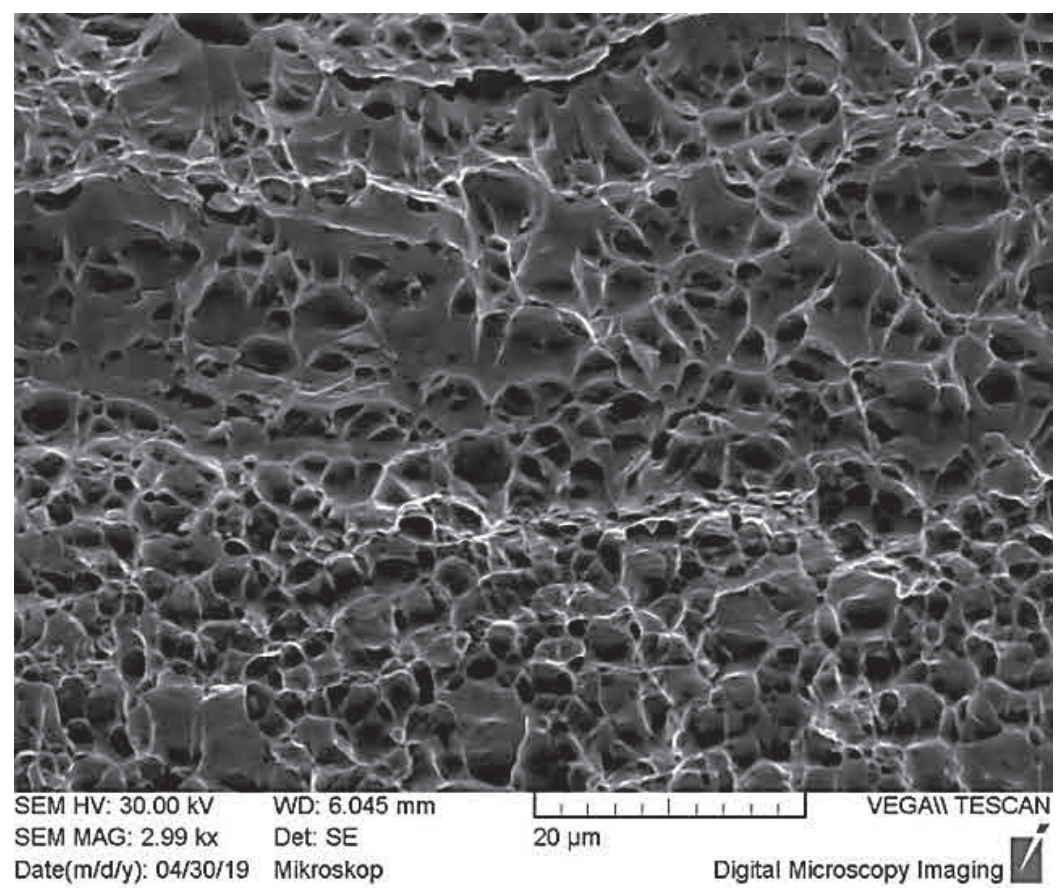

Figure 4 SEM image of ductile fractured sample after dynamic tensile test

Tested samples are inspected in the scanning electron microscope, to observe the fracture behaviour. Both quasi-static and dynamic tensile tests have a clear ductile mode of fracture - see Figure 4. During the dynamic loading, the yielding point is started at $100 \mu$ s and it reaches the maximum stress condition at $250 \mu$ s and final fracture occurs at around $500 \mu \mathrm{s}$. A uniform distribution of time versus load can be seen during dynamic testing. Hence no adverse kind of fracture behaviour is seen even at higher strain rate.

\subsection{Hardness values}

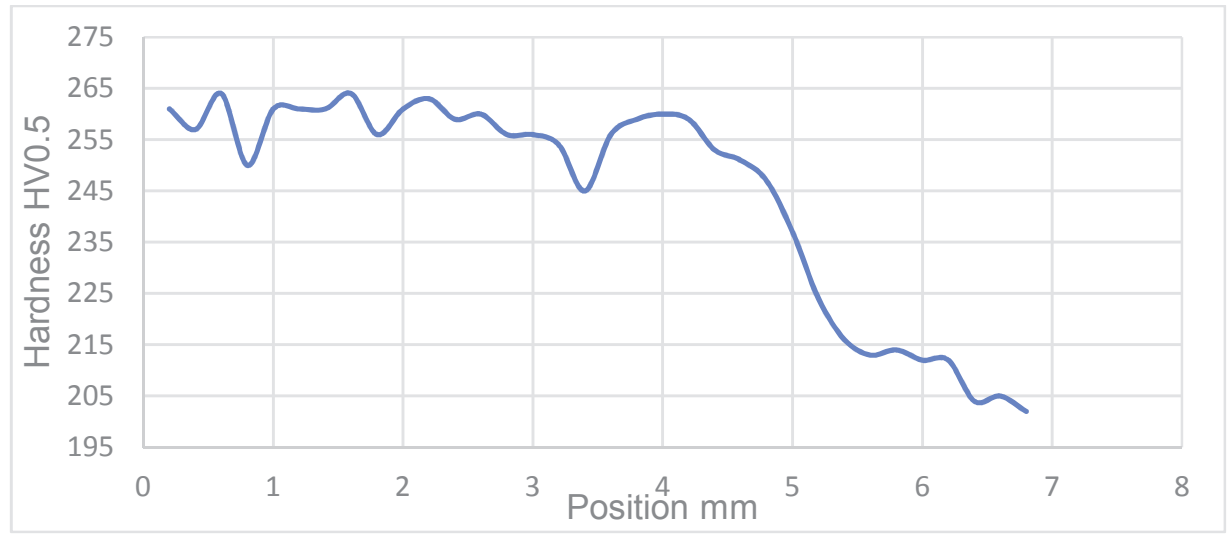

Figure 5 Hardness versus position from fractured to unaffected end 
The spread of the strain hardening effect can be concluded with hardness measurement - see Figure 5. A higher value of hardness is recorded near the fracture end and continues up to 4 to $5 \mathrm{~mm}$ distance from fracture end. Strain hardening effect is directly proportional to the hardness. The higher value of hardness near the fracture and continues to be the same over a distance of 4 to $5 \mathrm{~mm}$ is attributed to the equal strain hardening and load distribution in the sample during dynamic loading.

\section{CONCLUSIONS}

Strain rate sensitivity and fracture behaviour of the DP500xxx dual phase steel is studied in both quasi-static and dynamic loading conditions. Hardness values are measured after the dynamic testing to understand the spread of the strain hardening effect. Following conclusions can be made from the above research work,

- The substantial difference between the quasi-static and dynamic stress-strain curve indicates the sensitivity of the DP500xxx dual phase steel to the strain rate.

- The geometry of the sample, testing method and thickness of the sample have a considerable effect on the dynamic testing results.

- A clear ductile fracture can be seen even after the dynamic loading at the strain rate of $1060 \mathrm{~s}^{-1}$.

- The equal distribution of plastic stresses and strain hardening effect during the dynamic loading can be concluded with hardness values.

- $\quad$ Studying the dislocation density before and after the dynamic testing gives a better understanding of the strain hardening effect at the granular level.

\section{ACKNOWLEDGEMENTS}

The research published in this paper was supported by the project Number SGS 2019010.

\section{REFERENCES}

[1] WANG, H.S., YUAN, G., KANG, J., CAO, G.M, LI, CH.G., MISRA, R.D.K. and WANG, G.D. Microstructural evolution and mechanical properties of dual phase steel produced by strip casting. Materials Science and Engineering. 2017.vol. 703A, pp. 486-495.

[2] RADWANSKI, K., KUZIAK, R. and ROZMUS, R. Structure and mechanical properties of dual-phase steel following heat treatment simulations reproducing a continuous annealing line. Archives of civil and mechanical engineering. 2019, vol. 19, pp. 453 - 468.

[3] RAD, V.F., KHAMEDI, R. and MORADI, A.R. The effect of martensite volume fraction on topography of dual phase steels. Materials Letters. 2019, vol. 239, pp. 21-23.

[4] GHASSEMI-ARMAKI, H., MAAß, R., BHAT, S.P., SRIRAM, S., GREER, J.R. and KUMAR, K.S. Deformation response of ferrite and martensite in a dual-phase steel. Acta Materialia. 2014. vol. 62, pp. 197- 211.

[5] ENNIS, B.L, BOS, C., AARNTS, M.P., LEE, P.D. and JIMENEZ-MELERO, E. Work hardening behaviour in banded dual phase steel structures with improved formability. Materials Science and Engineering. 2018. vol. 713A, pp. 278-286.

[6] TASAN, C.C., DIEHL, M., YAN, D, BECHTOLD, M., ROTERS, F., SCHEMMANN, L., ZHENG, C., PERANIO, N, PONGE, D., KOYAMA, M., TSUZAKI, K. and RAABE, D. An Overview of Dual-Phase Steels: Advances in Microstructure-Oriented Processing and Micromechanically Guided Design. Annual Review of Materials Research. 2015. vol. 45, pp. 391-431.

[7] SCHMIDOVÁ, E. and HANUS, P. Weldability of Al-Si Coated High Strength Martensitic Steel. Periodica Polytechnica Transportation Engineering. 2018. vol. 41A, no. 2, pp.127-132. 
[8] SUNILKUMAR, M. R. and SCHMIDOVA, E. Strength and plastic deformation of dual-phase steel in static and dynamic conditions. In SEMIDOC 2019: 24th International Seminar of PhD Students.Žilina: Žilinská universita v Žilině, 2019, pp. 1-6.

[9] QIN, J., CHEN, R., WEN, X., LIN, Y., LIANG, M. and LU, F. Mechanical behaviour of dual-phase high-strength steel under high strain rate tensile loading. Materials Science and Engineering. 2013. vol. 86A, pp. 62-70.

[10] XIA, P., VERCRUYSSE, F., PETROV, R., SABIROV, I., CASTILLO-RODRÍGUEZ, M. and VERLEYSEN, P. High strain rate tensile behavior of a quenching and partitioning (Q\&P) Fe-0.25C-1.5Si-3.0Mn steel. Materials Science and Engineering. 2019. vol. 745A, pp. 53-62.

[11] SHAKERIFARD, B., GALAN LOPEZ, J., TABOADA LEGAZA, M.C., VERLEYSEN, P. and KESTENS, L.A.I. Strain rate dependent dynamic mechanical response of bainitic multiphase steels. Materials Science and Engineering. 2019. vol. 745A, pp. 279-290.

[12] DAS, A., TARAFDER, S., SIVAPRASAD, S. and CHAKRABARTI, D. Influence of microstructure and strain rate on the strain partitioning behaviour of dual phase steels. Materials Science and Engineering. 2019. vol. 754A, pp. 348-360. 